\title{
The Effect of Low and High Vacuum Drainage on the Postoperative Drainage of Breast Cancer: Insights from a Prospective, Non-Inferiority, Randomized Clinical Trial
}

This article was published in the following Dove Press journal:

Cancer Management and Research

\author{
Wanyi Lin ${ }^{1,2, *}$ \\ Yaping Yang $\mathbb{D}^{1,2, *}$ \\ Wenjing Zhong ${ }^{1,2}$ \\ Qun Lin ${ }^{1,2}$ \\ Nanyan Rao ${ }^{1-3}$ \\ Gehao Liang ${ }^{1,2}$ \\ Yun Ling ${ }^{1,2}$ \\ Zihao Liu ${ }^{1,2}$ \\ Qing Luo ${ }^{1,2}$ \\ Zhenluan Tian ${ }^{1,2}$ \\ Chang Gong ${ }^{1,2,4}$
}

'Guangdong Provincial Key Laboratory of Malignant Tumor Epigenetics and Gene Regulation, Sun Yat-Sen Memorial Hospital, Sun Yat-Sen University, Guangzhou 510120, People's Republic of China; 'Department of Breast Surgery, Breast Tumor Center, Sun Yat-Sen Memorial Hospital, Sun Yat-Sen University, Guangzhou 510120, People's Republic of China; ${ }^{3}$ Department of Oncoplastic and Reconstruction Breast Surgery, Breast Tumor Center, Sun Yat-Sen Memorial Hospital, Sun Yat-Sen University, Guangzhou 510120, People's Republic of China; ${ }^{4}$ Bioland Laboratory, Guangzhou Regenerative Medicine and Health Guangdong Laboratory, Guangzhou, 510005, People's Republic of China

*These authors contributed equally to this work

Correspondence: Chang Gong Department of Breast Surgery, Breast Tumor Center, Sun Yat-Sen Memorial Hospital, Sun Yat-Sen University, 107 Yanjiang West Road, Guangzhou 510120, People's Republic of China

Email gchang@mail.sysu.edu.cn
Background: Vacuum drains have been extensively applied to prevent seroma formation after breast surgery. However, the usage of negative suction drainage is mainly determined by surgeon's experience and preferences. The aim of this study is to prospectively compare the drain effect after breast surgery between the low and high vacuum drains.

Methods: This prospectively randomized trial (from January 2018 to June 2019) involved 188 patients who were subjected to modified radical mastectomy (group $\mathrm{A}, \mathrm{n}=128$ ) or immediate breast reconstruction with implants (group $B, n=60$ ). In each group, patients were randomized to receive high vacuum drain (pressure $=98 \mathrm{kPa}$ ) or low vacuum drain (pressure $=12 \mathrm{kPa}$ ) after surgery. Days of drain permanence, which means the duration of drainage, was the primary endpoint.

Results: According to the comparison of days of drain permanence, the effect of a low vacuum drain is not inferior to a high vacuum drain in group A (pectoral drain, $P<0.001$; axillary drain, $P<0.001$ ) or group $\mathrm{B}$ (submuscular drain, $P=0.002$ ). The complications frequently occurred on patients with high vacuum drain $(11.7 \%)$, such as seroma formation. The expense of low vacuum drain was significantly lower than high vacuum drain in both groups $(P<0.01)$.

Conclusion: The drain effect of the low vacuum drain is not inferior to a high vacuum drain in both group A and group B. The low vacuum drain was effective, relatively cheap, and did not increase the incidence of complications; it is therefore more recommended after breast surgery. Keywords: breast surgery, days of drain permanence, postoperative drain

\section{Introduction}

Breast cancer is the most commonly diagnosed cancer and the leading cause of cancer death among females. ${ }^{1}$ Breast surgery, including breast conservation surgery and mastectomy with or without axillary dissection, is one of the most important therapies for breast cancer. Zhang et $\mathrm{al}^{2}$ reported that the modified radical mastectomy (MRM) remained the primary strategy for treating breast cancer. However, with the advancing technology and increasing individual requirements, the proportion of breast reconstruction surgery is up to $10 \%$ and prosthesis-based reconstruction has a $>10$ times increase from 2012 to 2015 in China. ${ }^{3}$

Seroma formation, a fluid collection in the wound, is known as the most common postoperative complication of breast cancer. ${ }^{4-7}$ The reported incidence 
varies from $20 \%$ to $50 \%,{ }^{8}$ and the closed suction drains were first applied to treat the mastectomy wound to decrease the formation of seroma in $1947,{ }^{9}$ and now are widely used after almost all the breast surgeries. However, there is no well-established consensus or guideline to advise the use of drain. What type of vacuum drainage (eg, high or low) should be used mainly depends on the experience and preferences of the surgeon. ${ }^{10,11}$ Surgeons who prefer high vacuum drains consider high negative pressure can high-efficiently evacuate the fluid and reduce the dead space promptly. ${ }^{12,13}$ But some studies reported that the high negative pressure may prevent the leaking lymphatic channels and blood vessels from closing, leading to continuous drainage and a higher incidence of seroma formation. ${ }^{14-16}$ Few researchers compared the distinct drain effect between the low and high vacuum drain and made obscured conclusions. ${ }^{14,17}$ In addition, it is worth noting that the price of a high vacuum drain bottle is much higher than the low vacuum drain bottle. Therefore, this prospective study is aimed at testing the drain effect from low and high vacuum drainage.

\section{Materials and Methods}

This study is based on a prospective, randomized clinical trial carried out at the Department of Breast Surgery, Breast tumor center, Sun Yat-Sen Memorial Hospital in Guangzhou, China. It was approved by the ethics committee of Sun Yat-Sen Memorial Hospital ([2018]03). Written informed consent was obtained from all participants in the study. Eligible criteria: patients were all female, aged 18-80 years; newly diagnosed and operable carcinoma of the breast; body mass index (BMI) was 16-36; scheduling for MRM or immediate breast reconstruction with implants. Excluded criteria: patients did not receive MRM or immediate breast reconstruction with implants; received radiotherapy historically; with diabetes; with mental illness; with intelligent abnormal.

The low vacuum drain was KANGLI $^{\circledR}$ (SUNLIGHT MEDICAL, China), a W-II type wound drainage with a maximum negative pressure of $-12 \mathrm{kPa}$. The high vacuum drain was $\mathrm{Jet}^{-\mathrm{Vac}^{\circledR}}{ }^{\circledR} \mathrm{pfm}$ medical, Germany), a Redon type wound drainage with the maximum negative pressure of $-98 \mathrm{kPa}$ (Supplementary Figure S1, Supplementary Table S1). The negative suction drain used in this study, with large capacity and simplicity of operation, has been widely used in our hospital.

According to the professional advice and patients' personal intentions, patients were subjected to modified radical mastectomy (group A) or immediate breast reconstruction with implants (group B). In each group, patients were randomized to use a high vacuum drain (HVD group) or low vacuum drain (LVD group) after surgery. Pectoral drainages and axillary drainages were used for those who received MRM. And submuscular drains were routinely placed in the submuscular pocket for patients who received immediate breast reconstruction. ${ }^{10}$ Once the patients who were operated on with immediate breast reconstruction had axillary lymph node dissection, another drainage would be placed in the axillary region.

The main endpoint was the days of drain permanence (DDP), which was calculated from the following day of surgery to the day that drain was removed. The drain was removed when the drainage amount was less than $30 \mathrm{~mL}$ per day for 2 consecutive days. ${ }^{18}$

The secondary outcome measures included total amount of aspirate after operation, cost of negative suction bottles, and postoperative pain score. The daily amount of each drainage was calculated at 7 a.m. every day after the operation. As soon as the drainage was removed, its daily amount was then summed up as the total drain volume. Postoperative pain scores were assessed by using Numeric Rating Scale (NRS). NRS, which is a segmented numeric version of Visual Analog Scale, is a 11-point onedimensional numeric scale. ${ }^{19}$ The line of NRS was equally marked from 0-10 for score from left to right. 0 represents "no pain", while 10 represents "unbearable pain". 19,20 Higher score means greater intensity of pain. ${ }^{19}$ Patients were educated about NRS on the day after the surgery and asked to mark the score on the line for consecutive 3 days after the surgery.

The negative vacuum system related complications (eg, leaks of the vacuum bottles, seepage from the drainage pipe, tube loss, blocking of the tube), and the wound related complications (eg, subcutaneous seroma, wound infection, delayed wound healing, skin flap necrosis) were recorded as the indexes of safety.

Sample size calculation was based on a pilot study in the Department of Breast Surgery, Breast tumor center, Sun YatSen Memorial Hospital in Guangzhou, China. The DDP of group A was $8.0 \pm 1.4$ days in the HVD group and $9.0 \pm 2.0$ days in the LVD group. We assumed that the magnitude of the margin of non-inferiority was -2.0 days, the actual mean difference between the LVD and HVD group was -1.0 days in group A. In group B, the DDP was $8.7 \pm 1.0$ days in the HVD group and 9.5 \pm 2.6 days in the LVD group. We assumed the magnitude of the margin of non-inferiority 
was -2.5 days, the actual mean difference between LVD and HVD group was -0.8 days in group B. A non-inferiority test for two proportions with a $97.5 \%$ confidence interval (alpha $=0.025$ ) and $90 \%$ power (1-beta $=0.9$ ) sample size calculation showed that 128 patients needed to be randomized in group A (ie, modified radical mastectomy group) and 60 patients needed to be enrolled in group B (ie, immediate breast reconstruction group).

In group A and group B, patients were randomized to use a low vacuum drain or high vacuum drain. Randomization was performed by a statistical expert according to a predefined randomization table. The clinical assistant, performing the follow-up by phone, was unknown to each patient's treatment group.

Statistical analysis was performed using IBM SPSS Statistics software version 25. Qualitative data was compared between high and low vacuum drain groups using Chi-square. Quantitative data was expressed as mean \pm standard deviation and compared using Independent-samples $T$-test. The differences of DDP in each subgroup were compared by Non-inferiority Test, and $P$-values of $<0.025$ were assumed to be statistically significant. Total drain volume, cost of bottles, and pain score between the low and high negative drain group were compared by using the Independent-samples $T$ test. $P$-values of $<0.05$ were assumed to be statistically significant.

MRM surgery was performed by two chief surgeons at the Department of Breast Surgery in our unit using a standardized technique with electrocautery. Immediate breast reconstruction was performed by the chief surgeon of the Department of Oncoplastic and Reconstruction Breast Surgery in our unit.

\section{Results}

From January 2018 to June 2019, 208 patients with breast cancer were evaluated for participating in the clinical trial (Figure 1). Among them, 188 patients were finally enrolled into group A $(n=128)$ or group $B(n=60)$. The reasons for exclusion were not meeting inclusion criteria $(\mathrm{n}=19)$ and missing clinical data $(\mathrm{n}=1)$. In group $\mathrm{A}$, patients were randomized into the LVD group $(n=64)$ or HVD group $(n=64)$. In group $B$, patients were randomized into the LVD group $(n=30)$ or HVD group $(\mathrm{n}=30)$.

Baseline demographic and clinical characteristics were similar between the LVD group and HVD group in both group A and group B, in terms of age, weight, height,

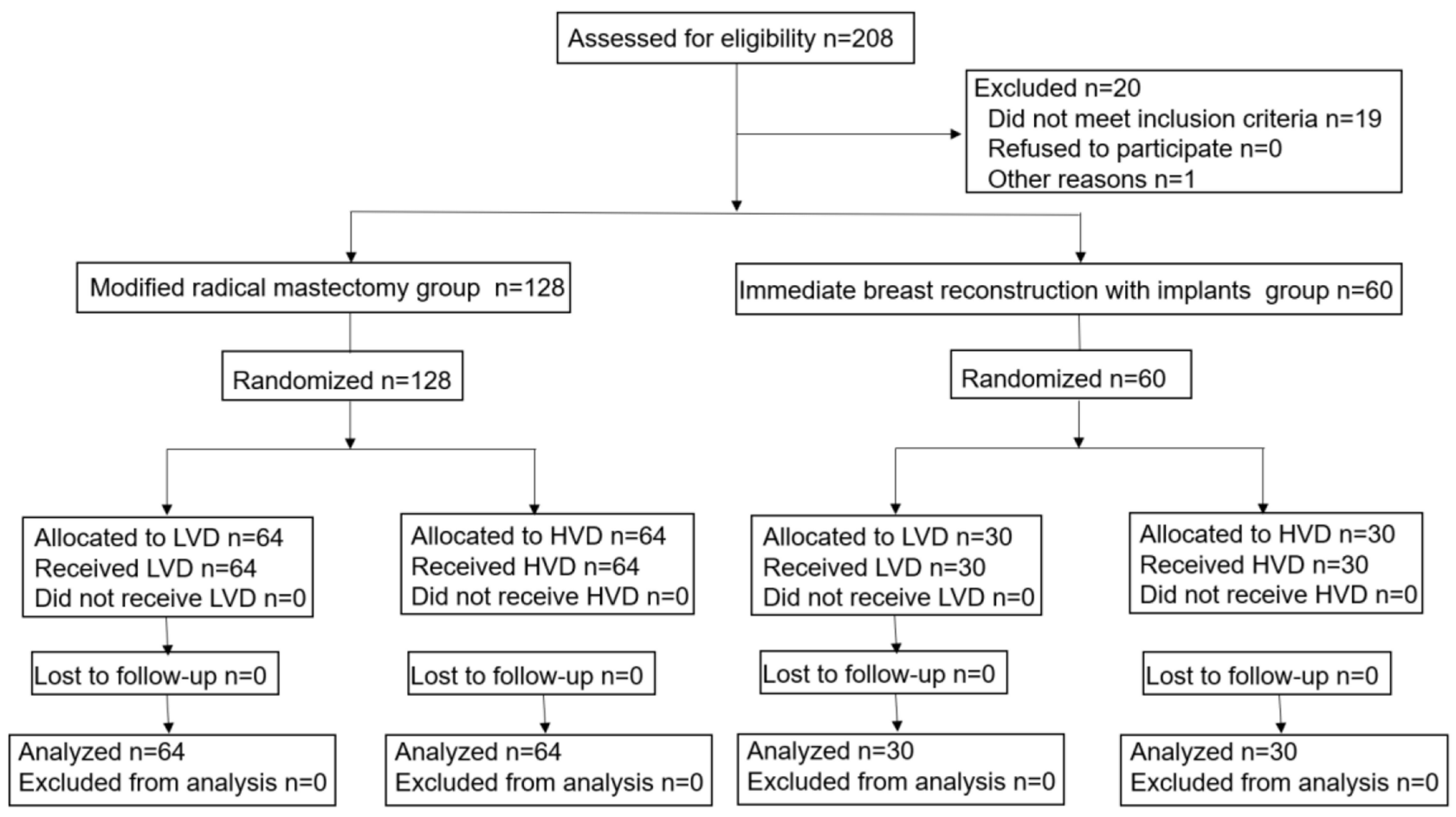

Figure I Consort flow diagram. Adapted from Schulz KF, Altman DG, Moher D. The CONSORT Group (20I0) CONSORT 20I0 Statement: Updated Guidelines for Reporting Parallel Group Randomised Trials. PLoS Med. 7(3): el00025I. Copyright: @ 2010 Schulz et al. Creative Commons Attribution License. ${ }^{21}$

Abbreviations: LVD, low vacuum drain; HVD, high vacuum drain. 
BMI, total protein, albumin, hemoglobin, pathological pattern, TNM stage, number of lymph removal, number of positive lymph node, volume of the breast, molecular subtyping, and the proportion of patients accepted neoadjuvant chemotherapy $(P>0.05)$ (Table 1$)$.

\section{Primary Outcome}

Mean DDP and $P$-value for the LVD and HVD group of each subgroup are presented in Figure 2. Based on the comparison of DDP, the drain effect of low vacuum drain is not inferior to that of the high vacuum drain in group

Table I Baseline, Tumor and Treatment Characteristics of Patients Undergoing Modified Radical Mastectomy and Immediate Breast Reconstruction with Implants Surgery

\begin{tabular}{|c|c|c|c|c|c|c|}
\hline & \multicolumn{3}{|c|}{ Modified Radical Mastectomy Group (A) } & \multicolumn{3}{|c|}{$\begin{array}{l}\text { Immediate Breast Reconstruction with Implants } \\
\text { Group (B) }\end{array}$} \\
\hline & $\begin{array}{l}\text { LVD Group } \\
(n=64)\end{array}$ & $\begin{array}{l}\text { HVD Group } \\
(n=64)\end{array}$ & $P$-value & $\begin{array}{l}\text { LVD Group } \\
(n=30)\end{array}$ & $\begin{array}{l}\text { HVD Group } \\
(n=30)\end{array}$ & $P$-value \\
\hline Mean age (years) & $51.1 \pm 9.1$ & $52.1 \pm I I .1$ & 0.57 & $40.8 \pm 9.4$ & $42.2 \pm 6.7$ & 0.50 \\
\hline Mean weight (Kg) & $57.7 \pm 7.9$ & $57.6 \pm 9.1$ & 0.95 & $57.2 \pm 9.0$ & $56.1 \pm 5.6$ & 0.56 \\
\hline Mean height $(m)$ & $1.6 \pm 0.1$ & $1.6 \pm 0.1$ & 0.58 & $1.6 \pm 0.1$ & $1.6 \pm 0.0$ & 0.91 \\
\hline Mean BMI $\left(\mathrm{Kg} / \mathrm{m}^{2}\right)$ & $23.3 \pm 2.9$ & $23.5 \pm 3.4$ & 0.80 & $22.3 \pm 3.2$ & $21.8 \pm 1.8$ & 0.48 \\
\hline \multicolumn{7}{|l|}{ BMI grade (\%) } \\
\hline$<18.5$ & $2(3.1)$ & $3(4.7)$ & 0.20 & I (3.3) & I (3.3) & 0.28 \\
\hline $18.5-23.9$ & $35(54.7)$ & $38(59.4)$ & & $21(70.0)$ & $26(86.7)$ & \\
\hline $24.0-27.9$ & $24(37.5)$ & $15(23.4)$ & & $7(23.3)$ & $3(10.0)$ & \\
\hline$\geq 28$ & $3(4.7)$ & $8(12.5)$ & & I (3.3) & 0 & \\
\hline Mean total protein $(g / L)$ & $67.7 \pm 6.8$ & $67.4 \pm 6.6$ & 0.79 & $67.4 \pm 9.3$ & $68.9 \pm 6.5$ & 0.48 \\
\hline Mean albumin $(g / L)$ & $39.5 \pm 3.5$ & $39.3 \pm 3.9$ & 0.78 & $40.9 \pm 3.3$ & $41.2 \pm 3.8$ & 0.71 \\
\hline Mean hemoglobin $(\mathrm{g} / \mathrm{L})$ & $120.8 \pm 20.0$ & $121.9 \pm 17.1$ & 0.74 & $124.3 \pm 9.6$ & $118.8 \pm 19.1$ & 0.16 \\
\hline \multicolumn{7}{|l|}{ Pathology pattern (\%) } \\
\hline IDC & $57(89.1)$ & $57(89.1)$ & 1.00 & $16(53.3)$ & $19(63.4)$ & 0.60 \\
\hline Other & $7(10.9)$ & $7(10.9)$ & & $14(46.7)$ & II (36.6) & \\
\hline \multicolumn{7}{|l|}{ T size $(\%)$} \\
\hline $\mathrm{T} \leq 2 \mathrm{~cm}$ & $20(3 \mid .3)$ & $16(25.0)$ & 0.57 & $18(60.0)$ & I5 (50.0) & 0.69 \\
\hline $2 \mathrm{~cm} \leq \mathrm{T} \leq 5 \mathrm{~cm}$ & $35(54.7)$ & $35(54.7)$ & & $7(23.3)$ & $10(33.3)$ & \\
\hline $\mathrm{T} \geq 5 \mathrm{~cm}$ & $9(14.1)$ & $13(20.3)$ & & $5(16.6)$ & $5(16.7)$ & \\
\hline \multicolumn{7}{|l|}{ Node number (\%) } \\
\hline No & $30(46.9)$ & $18(28.1)$ & 0.08 & $24(80.0)$ & $23(76.7)$ & 0.63 \\
\hline $\mathrm{NI}$ & $18(28.1)$ & $31(48.4)$ & & $2(6.7)$ & $5(16.7)$ & \\
\hline N2 & $8(12.5)$ & $6(9.4)$ & & $3(10.0)$ & $2(6.7)$ & \\
\hline N3 & $8(12.5)$ & $9(14.1)$ & & I (3.3) & 0 & \\
\hline Mean number of $L N$ resected & $18.4 \pm 8.5$ & $19.7 \pm 8.3$ & 0.39 & $10.6 \pm 9.9$ & $7.3 \pm 7.7$ & 0.16 \\
\hline Mean number of positive $\mathrm{LN}$ & $3.2 \pm 5.4$ & $4.3 \pm 6.1$ & 0.32 & $2.3 \pm 7.3$ & $0.5 \pm 1.3$ & 0.18 \\
\hline Mean breast volume $\left(\mathrm{cm}^{3}\right)$ & || $47.1 \pm 635.5$ & $1022.5 \pm 405.5$ & 0.19 & $638.9 \pm 259.2$ & $595.7 \pm 306.9$ & 0.56 \\
\hline \multicolumn{7}{|l|}{ Molecular subtyping (\%) } \\
\hline Luminal & $50(78.2)$ & 49 (76.6) & 0.83 & $26(86.7)$ & $24(80.0)$ & 0.73 \\
\hline Non-luminal & $14(2 \mid .8)$ & $15(23.4)$ & & $4(13.3)$ & $6(20.0)$ & \\
\hline \multicolumn{7}{|l|}{ NCT (\%) } \\
\hline No & $40(62.5)$ & $42(65.6)$ & 0.85 & $26(86.7)$ & $27(90.0)$ & 1.00 \\
\hline Yes & $24(37.5)$ & $22(34.4)$ & & $4(13.3)$ & $3(10.0)$ & \\
\hline
\end{tabular}

Notes: Continuous variables are presented as mean \pm standard deviation. Categorical variables in number (\%).

Abbreviations: LVD, low vacuum drain; HVD, high vacuum drain; BMI, body mass index; IDC, invasive ductal cancer; T, tumor; N, node; M, metastasis; LN, lymph node; NCT, neoadjuvant chemotherapy. 

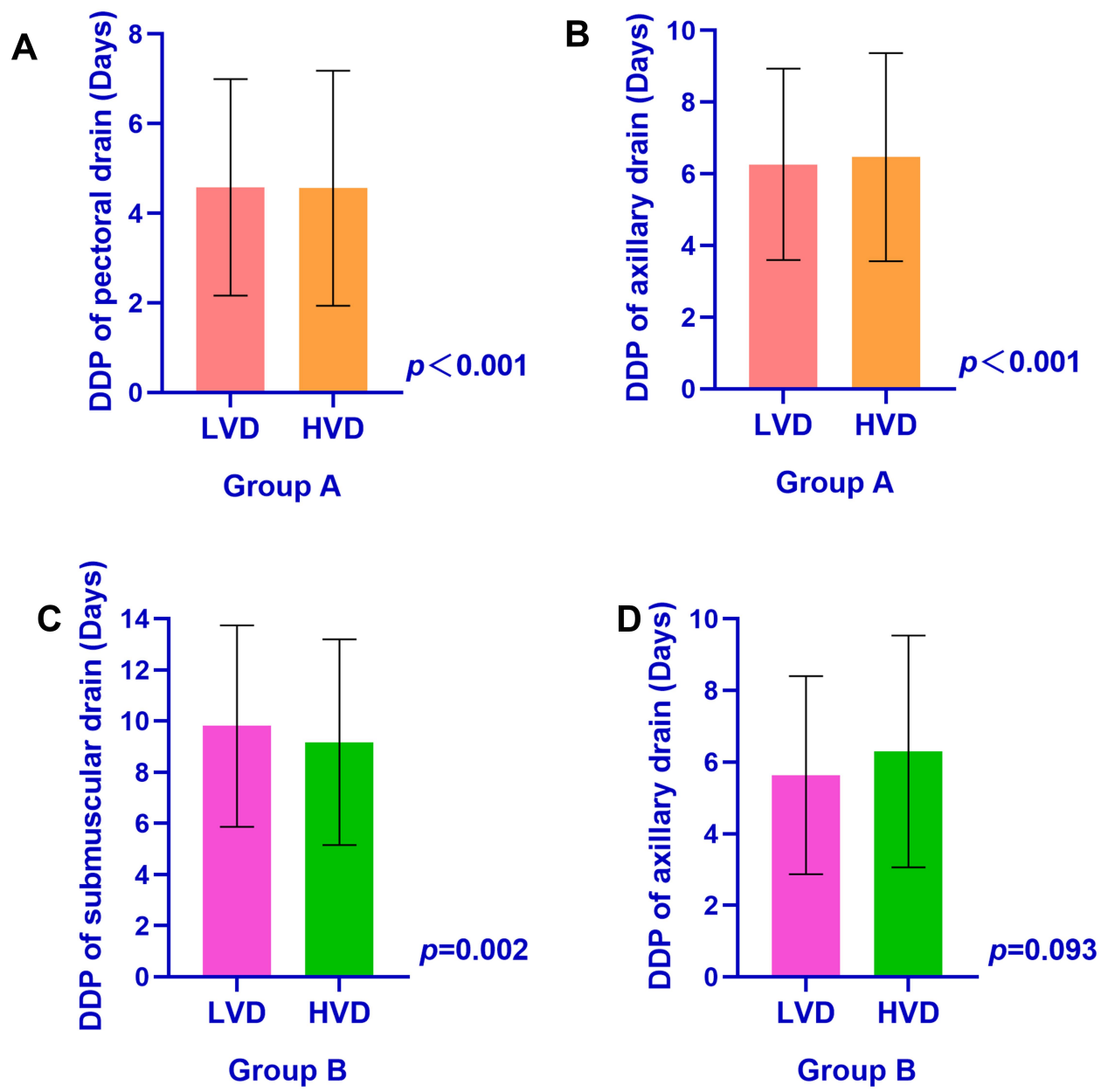

Figure 2 Comparison of DDP between low and high vacuum drain group of group A (A pectoral drain, B axillary drain) and group B (C submuscular drain, $\mathbf{D}$ axillary drain), respectively. Values shown as mean \pm standard deviation, Non-inferiority Test.

Abbreviations: LVD, low vacuum drain; HVD, high vacuum drain; DDP, the days of drain permanence.

A (pectoral drain, $4.6 \pm 2.4$ days vs $4.6 \pm 2.6$ days, $P<0.001$; axillary drain, $6.3 \pm 2.7$ days vs $6.5 \pm 2.9$ days, $P<0.001$ ) or group B (submuscular drain, $9.8 \pm 3.9$ days vs $9.2 \pm 4.0$ days, $P=0.002$ ). However, the comparison of axillary DDP in group $\mathrm{B}$ did not show a similar result. In group $\mathrm{B}$, the mean DDP of the axillary drain was $5.6 \pm 2.8$ days in the LVD group and $6.3 \pm 3.2$ days in the HVD group $(P=0.093)$.

\section{Secondary Outcome}

No difference in the total drainage volume was recognized between the low and high vacuum drain group (group A: pectoral drain, $180.1 \pm 160.3 \mathrm{~mL}$ vs 192.1 $\pm 214.6 \mathrm{~mL}, P=0.72$, axillary drain, $329.5 \pm 237.5 \mathrm{~mL}$ vs $367.0 \pm 305.3 \mathrm{~mL}, P=0.44$; group $\mathrm{B}$ : submuscular drain, $692.0 \pm 397.6 \mathrm{~mL}$ vs $509.3 \pm 345.4 \mathrm{~mL}, P=0.06$, axillary drain, $295.9 \pm 277.5 \mathrm{~mL}$ vs $299.5 \pm 241.6 \mathrm{~mL}, P=0.98$ ) (Figure 3).
When comparing the cost of negative pressure drainage device, the expense of the low vacuum drainage system was significantly lower than the cost of the high vacuum drainage system in both group A and group B (group A: 76.5 \pm 26.2 Chinese Yuan (CNY) vs 1925.5 $\pm 583.1 \mathrm{CNY}, P<0.01$; group B: 87.3 $\pm 37.0 \mathrm{CNY}$ vs 1985.1 $\pm 770.2 \mathrm{CNY}, P<0.01$ ) (Figure 4).

With respect to postoperative pain score in group A, the mean pain score for the low and high vacuum drain groups were grade $1.9 \pm 0.5$ and grade $2.4 \pm 0.6(P<0.01)$ (Figure 5). In group B, the mean pain score in the low and high vacuum drain groups were grade $3.0 \pm 0.7$ and grade $3.0 \pm 0.9(P=1.00)$ (Figure 5)

\section{Index of Safety}

Adverse event information was continuously recorded until the removal of negative suction drain. In general, the incidence of wound complications among patients shows no difference between the low and high vacuum drain (5.3\% vs $7.4 \%$, 
A
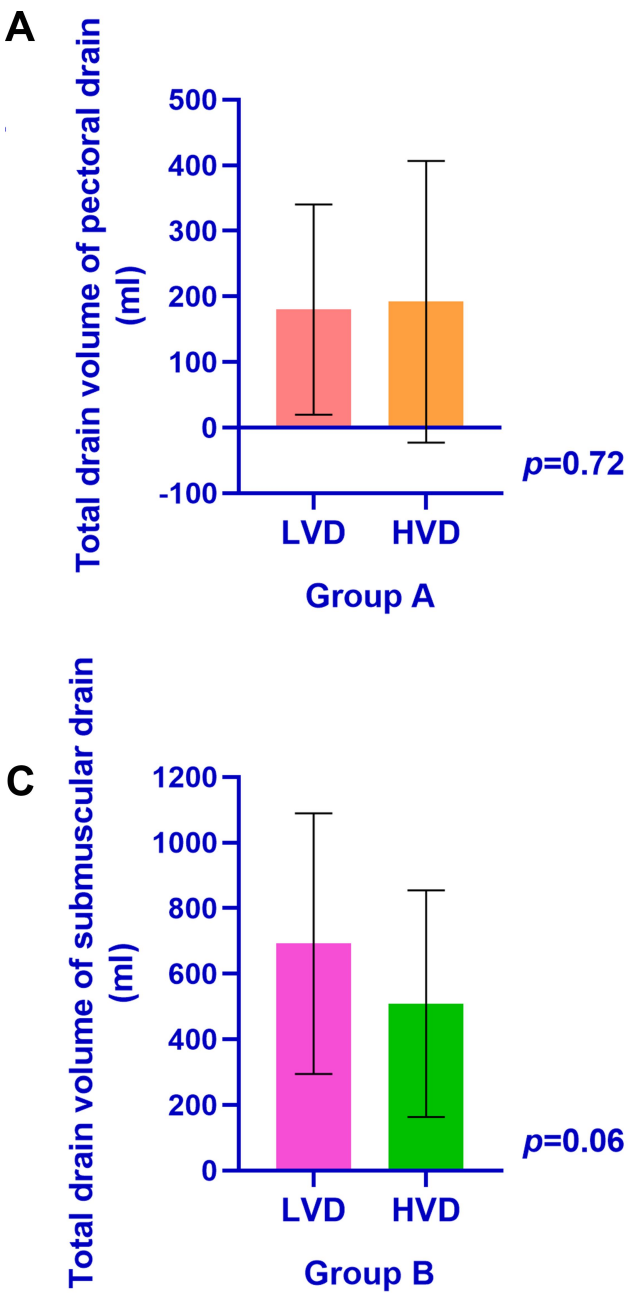

B.

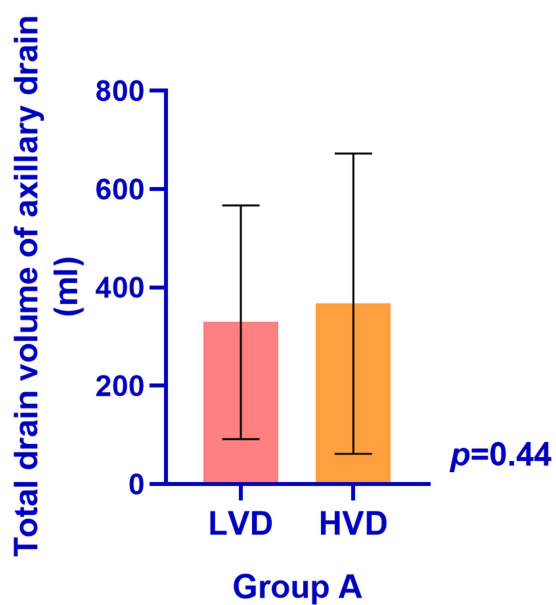

Group A

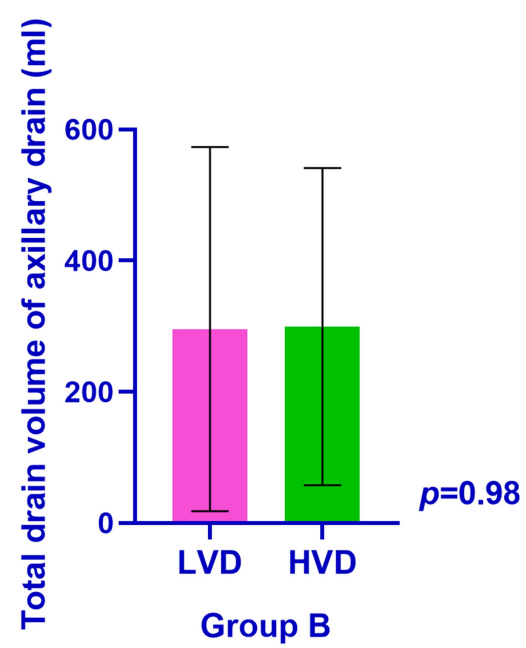

Figure 3 Comparison of total drain volume between low and high vacuum drain group of group A (A pectoral drain, B axillary drain) and group B (C submuscular drain, D axillary drain), respectively. Values shown as mean \pm standard deviation, Independent Samples Test.

Abbreviations: LVD, low vacuum drain; HVD, high vacuum drain.
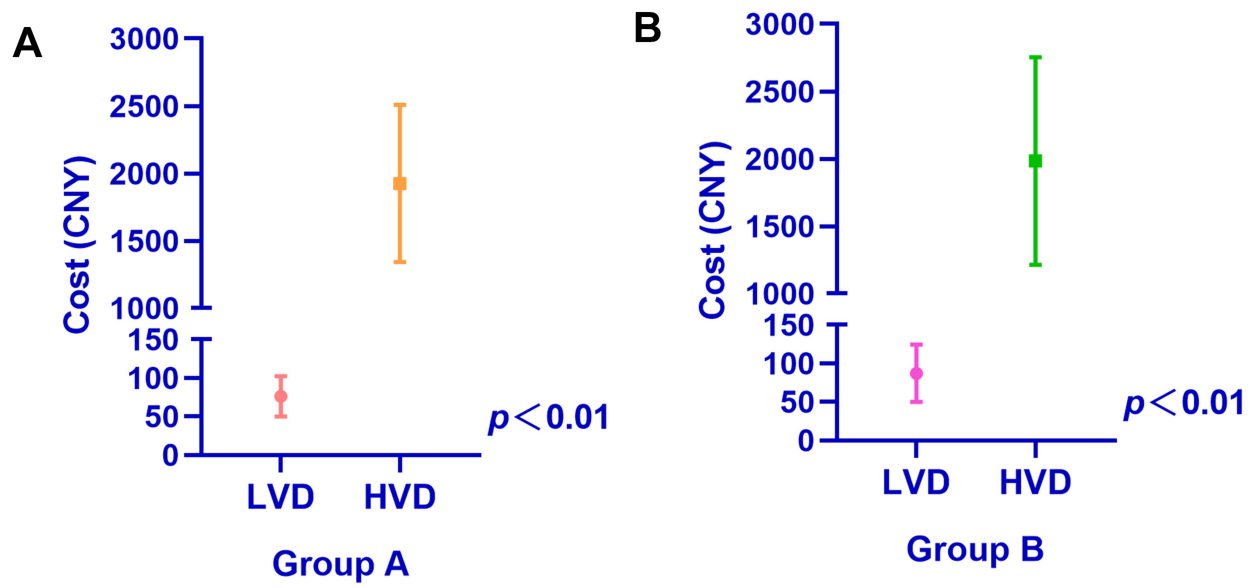

Figure 4 Comparison of cost between low and high vacuum drain group of group A (A: Group A) and group B (B: Group B) respectively. Values shown as mean \pm standard deviation, Independent Samples Test.

Abbreviations: LVD, low vacuum drain; HVD, high vacuum drain; CNY, Chinese Yuan. 
A

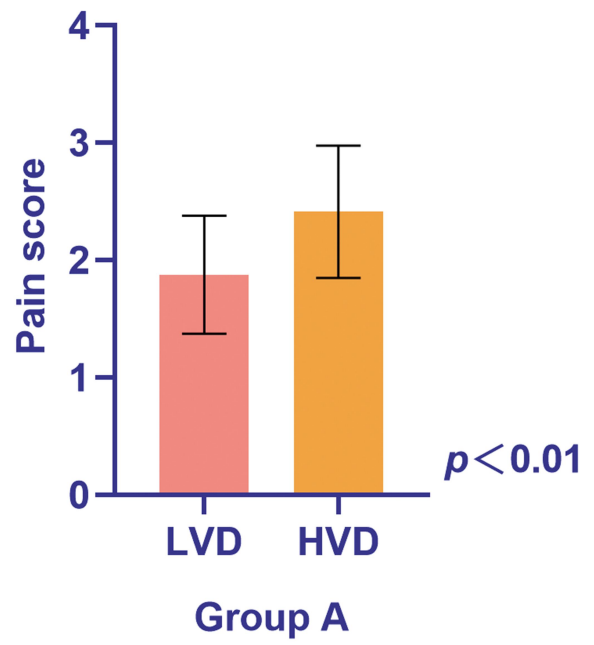

B

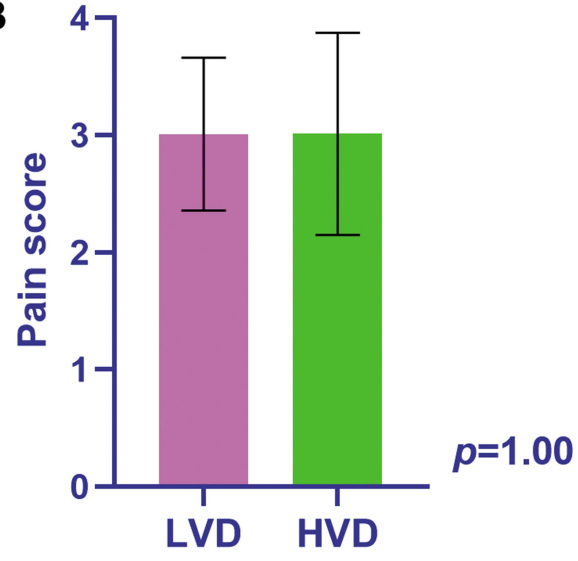

Group B

Figure 5 Comparison of pain score between low and high vacuum drain group of group A (A: Group A) and group B (B: Group B), respectively. Values shown as mean \pm standard deviation, Independent Samples Test.

Abbreviations: LVD, low vacuum drain; HVD, high vacuum drain.

$P=0.60$ ) (Table 2). No difference was found between low and high vacuum drain when comparing the incidence of drain complications ( $1.1 \%$ vs $4.3 \%, P=0.37$ ) (Table 2 ).

\section{Discussion}

In this prospective, non-inferiority, randomized study, we found that the use of a low vacuum drain had a similar drain effect, less cost, and less complications compared to a high vacuum drain. Our hypothesis that the drain effect of the low vacuum drain was not inferior to the high vacuum drain after MRM or breast reconstruction was validated by our results.

Several previous studies failed to address the drainage effect of different vacuum drain system after breast

Table 2 Incidence of Wound Complications and Drain Complications

\begin{tabular}{|c|c|c|c|}
\hline & \multicolumn{3}{|l|}{ Total } \\
\hline & LVD $(n=94)$ & HVD (n=94) & $P$-value \\
\hline Wound complications & $5(5.3 \%)$ & 7 (7.4\%) & 0.60 \\
\hline Wound poor healing & I (I.I\%) & 0 & \\
\hline Seroma formation & $4(4.3 \%)$ & $6(6.4 \%)$ & \\
\hline Wound infection & 0 & I (I.I\%) & \\
\hline Drain complications & I (I.I\%) & $4(4.3 \%)$ & 0.37 \\
\hline Blocking of the tube & I (I.I\%) & I (I.I\%) & \\
\hline $\begin{array}{l}\text { Seepage from the } \\
\text { drainage pipe }\end{array}$ & 0 & I (I.I\%) & \\
\hline Air leak of drainage pipe & 0 & I (I.I\%) & \\
\hline $\begin{array}{l}\text { Air leak of the vacuum } \\
\text { bottle }\end{array}$ & 0 & I (I.I\%) & \\
\hline
\end{tabular}

Abbreviation: LVD, low vacuum drain; HVD, high vacuum drain. surgery due to defective design of clinical trials, which in turn resulted in limited clinical recommendations: 1) retrospective studies with absence of randomization, ${ }^{10,14}$ 2) small sample sizes, ${ }^{10,14,17}$ 3) baseline of these studies not taking the factors that might influence the drainage, eg, the nutritional state, ${ }^{10,14,17}$ into account, and 4) using the total drain volume as a primary endpoint. ${ }^{10,14}$ This study prospectively compared the effect of low and high vacuum drainage by using DDP as a primary endpoint, with a larger sample size and less confounding factors.

According to the comparison of DDP, the drain effect of the low vacuum drain group is not inferior to that of the high vacuum drain group in group A (pectoral drain, $P<0.001$; axillary drain, $P<0.001$ ) and group B (submuscular drain, $P=0.002$ ). The comparison of axillary DDP between low and high vacuum drain group in group $B$ did not show the same result ( $P=0.093$ ). Only $35 \%$ patients in group $\mathrm{B}$ received the axillary lymph node dissection, indicating the inadequate sample size in this subgroup. However, these results showed drain effect of the low vacuum drain were not inferior to the high one, which were in accordance with most previous results. ${ }^{10,17}$ Chintamani et al ${ }^{14}$ used the DDP as a primary endpoint and found that the half vacuum drains were removed earlier than the full vacuum drains $(P<0.001)$. The results presented above indicate that the low vacuum drain has a similar drain effect compared to the high vacuum drain.

The clinical aim of using a negative suction drain is to reduce the incidence of seroma formation. In this study, the incidence of seroma formation was lower than the reported value, ie, $20-50 \%^{8}$ (LVD, 4.3\%, HVD, 6.4\%). Effective 
drainage and proper use of electrocautery contributes to the low incidence of seroma formation. ${ }^{21}$ However, apart from the seroma, there are other postoperative complications. Seroma formation is often seen as the latent cause of wound infection, delayed wound healing, and even surgical reinterventions. ${ }^{22-24}$ Chintamani et $\mathrm{al}^{14}$ found the half vacuum drains were removed earlier than the full vacuum drains without an increase of postoperative morbidity $(P<0.001)$, which is similar to the results of this study. In this study, the effect of a low vacuum drain was not inferior to that of a high vacuum drain, with no increase in the incidence of wound or drain complications.

The overall incidence of wound and drain complications was low, and the contrast in incidence of wound or drain complications between low and high vacuum drain is not significant. However, once the postoperative complications occurred, patients may need to change the drainage, receive debridement, or use antibiotics. Among patients using low vacuum drain with wound or drain complications, one in a hundred received debridement and four in a hundred regularly went to the clinic to evacuate the fluid. In contrast, for those patients who used the high vacuum drain, two received debridement and up to six regularly went to the clinic to evacuate the fluid. Not only does this increase the economic pressure of patients, it also increases the pain and psychological stress of patients.

No significant difference of pain score was found among patients receiving immediate breast reconstruction. This may be due to two different managements of the axillary in group B. In total, $65.0 \%$ of the patients in group B only received sentinel lymph node biopsy, thus did not receive axillary drain. Jain et $\mathrm{al}^{25}$ found patients with a drain after breast surgery had higher pain score than patients without a drain $(P<0.001)$. Therefore, patients with a submuscular drain and axillary drain may suffer more pain than patients with a submuscular drain alone. In this study, after patients received MRM, those using a high vacuum drain had a higher pain score than those using a low vacuum drain $(P<0.01)$. The negative suction drain may increase the pain of patients, but it seems that the high vacuum drain will cause more pain to the patients compared to the low vacuum drain, which can also disturb patients' daily life.

Economic cost is an important factor that should be considered in our clinical practice. To our knowledge, no studies have been carried out to investigate the cost of negative suction bottles. In our study, significant differences in the cost of drainage bottles were recognized between the low and high vacuum drain both in group $\mathrm{A}$ and group $\mathrm{B}(P<0.01)$. As mentioned above, patients with wound or drain complications might need to receive debridement or go to the clinic regularly to evacuate the fluid. These additional expenditures are not generally covered by health insurance in China, which will therefore increase the financial burden on the patients.

Several limitations may be related to this study. First, this is a single center-based study, which may have relatively poor representativeness of selected patients and selection deviation. Second, only $35.0 \%$ of the patients in group B received axillary lymph node dissection. The analysis of an axillary drain in group B had a limitation of the confounding for lymph node surgery. Third, there are different kinds of negative suction drain and not all the hospitals use the same kind of negative suction drain as we used in this study. But the low vacuum suction bottles are very common. We believed that other kinds of low vacuum drain also got the same effective drain effect. Further, the cost of treatment for the wound or drain complications was not recorded during the clinical trial, so the extra financial pressure on patients cannot be evaluated.

\section{Conclusion}

The drain effect of the low vacuum drain is not inferior to that of the high vacuum drainage in the modified radical mastectomy or immediate breast reconstruction group. As the low vacuum drain is effective and relatively cheap, and does not increase the incidence of complications, it is therefore more recommended in clinical operation after breast surgery.

\section{Abbreviations}

MRM, modified radical mastectomy; BMI, body mass index; HVD, high vacuum drain; LVD, low vacuum drain; DDP, days of drain permanence; NRS, Numeric Rating Scale; CNY, Chinese Yuan.

\section{Trial Registration}

Chinese Clinical Trial Registry (ChiCTR) (http://www. chictr.org/), ChiCTR1800014665, http://www.chictr.org. cn/edit.aspx?pid=24383\&htm=4.

\section{Data Sharing Statement}

The data used to support the findings of this study are available from the corresponding author upon request.

\section{Ethics Approval and Consent to Participate}

The study was approved by the ethics committee of Sun Yat-Sen Memorial Hospital ([2018]03) and was performed in accordance with the standards of the Declaration of 
Helsinki. Written informed consent was obtained from all participants in the study. All methods were performed in accordance with relevant guidelines and regulations.

\section{Author Contributions}

All authors made substantial contributions to the conception and design, acquisition of data, or analysis and interpretation of data; took part in drafting the article or revising it critically for important intellectual content; agreed to submit to the current journal; gave final approval of the version to be published; and agree to be accountable for all aspects of the work.

\section{Funding}

This work is supported by the National Key R\&D Program of China (2017YFC1309103 and 2017YFC1309104); the Natural Science Foundation of China (81672594, 81772836, 81872139, 82072907 and 82003311); Clinical Innovation Project of Bioland Laboratory (Guangzhou Regenerative Medicine and Health Guangdong Laboratory, 2018GZR0201004); Sun Yat-Sen Memorial Hospital Cultivation Project for Clinical Research (SYS-C-201805, SYS-Q-202004); Key Projects of The National Natural Science Foundation of China (51861125203); Project of Roche Solid Tumor Research Foundation of Chinese Society of Clinical Oncology (Y-Roche2019/2-0078); Sun Yat-Sen Memorial Hospital Yat-Sen Scientific Research Launch Project (YXQH201920); and Medical Science and Technology Research Fund of Guangdong Province (A2020391).

\section{Disclosure}

The authors declare that they have no conflicts of interest for this work.

\section{References}

1. Bray F, Ferlay J, Soerjomataram I, Siegel RL, Torre LA, Jemal A. Global cancer statistics 2018: GLOBOCAN estimates of incidence and mortality worldwide for 36 cancers in 185 countries. CA Cancer J Clin. 2018;68(6):394-424. doi:10.3322/caac.21492

2. Zhang B, Song Q, Zhang B, et al. A 10-year (1999 2008) retrospective multi-center study of breast cancer surgical management in various geographic areas of China. Breast. 2013;22(5):676-681. doi:10.1016/j.breast.2013.01.004

3. Huang N-S, Quan C-L, Ma L-X-X, et al. Current status of breast reconstruction in China: an experience of 951 breast reconstructions from a single institute. Gland Surg. 2016;5(3):278-286. doi:10.21037/ gs.2016.03.01
4. Bemmel AJMV, van de Velde CJH, Schmitz RF, Liefers GJ. Prevention of seroma formation after axillary dissection in breast cancer: a systematic review. Eur J Surg Oncol. 2011;37(10):8 29-835. doi:10.1016/j.ejso.2011.04.012

5. Ouldamer L, Bonastre J, Brunet-Houdard S, Body G, Giraudeau B, Caille A. Dead space closure with quilting suture versus conventional closure with drainage for the prevention of seroma after mastectomy for breast cancer (QUISERMAS): protocol for a multicentre randomised controlled trial. BMJ Open. 2016;6(4):e009903. doi:10.1136/ bmjopen-2015-009903

6. Wu Y, Wang S, Hai J, Mao J, Dong X, Xiao Z. Quilting suture is better than conventional suture with drain in preventing seroma formation at pectoral area after mastectomy. BMC Surg. 2020;20 (1):65. doi:10.1186/s12893-020-00725-8

7. Pan X, Huan J, Qin X. Potential risk factors for the development of seroma following mastectomy with axillary dissection. Mol Clin Oncol. 2015;3(1):222-226. doi:10.3892/mco.2014.430

8. Stehbens WE. Postmastectomy serous drainage and seroma: probable pathogenesis and prevention. ANZ J Surg. 2015;73(11):877-880. doi:10.1046/j.1445-2197.2003.02832.x

9. Murphey DRJ. The use of atmospheric pressure in obliterating axillary dead space following radical mastectomy. South Surg. 1947;13 (6):372-375

10. Pagliara D, Maxia S, Faenza M, Dessena L, Campus G, Rubino C. Low versus high vacuum suction drainage of the submuscular pocket in primary breast reconstruction: a retrospective study. Ann Plast Surg. 2018;80(4):339-343. doi:10.1097/SAP.0000000000001246

11. Suarez-Kelly LP, Pasley WH, Clayton EJ, Povoski SP, Carson WE, Rudolph R. Effect of topical microporous polysaccharide hemospheres on the duration and amount of fluid drainage following mastectomy: a prospective randomized clinical trial. BMC Cancer. 2019;19(1):99. doi:10.1186/s12885-019-5293-1

12. Wang H, Xiao G, Yang K. Suction drainage bottle radical effect observed in the prevention of post-operative complications in breast. Asia Pac Trad Med. 2012;8(12):143-144.

13. Yun J, Bian J, Wang L, Ling R, Yao Q. Application of vacuum high negative pressure drainage in breast cancer surgery. J Mod Oncol. 2007;11:1592-1593.

14. Chintamani C, Singh V, Singh JP, Bansal A, Saxena S. Half versus full vacuum suction drainage after modified radical mastectomy for breast cancer- a prospective randomized clinical trial [ISRCTN24484328]. BMC Cancer. 2005;5(1):11. doi:10.1186/14712407-5-11

15. Morris AM. A controlled trial of closed wound suction. Br J Surg. 2010;60(5):357-359. doi:10.1002/bjs. 1800600509

16. Bourke JB, Balfour TW, Hardcastle JD, Wilkins JL. A comparison between suction and corrugated drainage after simple mastectomy: a report of a controlled trial. Br J Surg. 2010;63(1):67-69. doi:10. 1002/bjs. 1800630115

17. Wedderburn A, Gupta R, Bell N, Royle G. Comparison between low and high pressure suction drainage following axillary clearance. Eur J Surg Oncol. 2000;26(2):142-144. doi:10.1053/ejso.1999.0757

18. Park J-W, Kim JH, Woo K-J. Intraoperative intercostal nerve block for postoperative pain control in pre-pectoral versus subpectoral direct-to-implant breast reconstruction: a retrospective study. Medicina (Kaunas). 2020;56(7):325. doi:10.3390/medicina56070325

19. Hawker GA, Mian S, Kendzerska T, French M. Measures of adult pain: Visual Analog Scale for Pain (VAS Pain), Numeric Rating Scale for Pain (NRS Pain), McGill Pain Questionnaire (MPQ), Short-Form McGill Pain Questionnaire (SF-MPQ), Chronic Pain Grade Scale (CPGS), Short Form-36 Bodily Pain Scale (SF-36 BPS), and Measure of Intermittent and Constant Osteoarthritis Pain (ICOAP). Arthritis Care Res (Hoboken). 2011;63:S240-S252. 
20. Kim H-J, Jung S-O. Comparative evaluations of single-item pain-intensity measures in cancer patients: numeric rating scale vs verbal rating scale. J Clin Nurs. 2020;29:2945-2952. doi:10.1111/jocn.15341

21. Schulz KF, Altman DG, Moher D. The CONSORT Group (2010) CONSORT 2010 Statement: Updated Guidelines for Reporting Parallel Group Randomised Trials. PLoS Med . 2010;7(3): e1000251. Available from: https://doi.org/10.1371/journal.pmed. 1000251 . Access November 20, 2020

22. Srivastava V, Basu S, Shukla VK. Seroma formation after breast cancer surgery: what we have learned in the last two decades. J Breast Cancer. 2012;15(4):373-380. doi:10.4048/jbc.2012.15.4.373

23. Sakkary MA. The value of mastectomy flap fixation in reducing fluid drainage and seroma formation in breast cancer patients. World J Surg Oncol. 2012;10(8):1-6. doi:10.1186/1477-7819-10-8
24. Bastelaar J, Granzier R, Roozendaal L, Beets G, Dirksen CD, Vissers Y. A multi-center, double blind randomized controlled trial evaluating flap fixation after mastectomy using sutures or tissue glue versus conventional closure: protocol for the Seroma reduction After Mastectomy (SAM) trial. BMC Cancer. 2018;18(1):830. doi:10.1186/s12885-018-4740-8

25. Rooij L, Kuijk S, Haaren E, et al. A single-center, randomized, non-inferiority study evaluating seroma formation after mastectomy combined with flap fixation with or without suction drainage: protocol for the Seroma reduction and drAin fRee mAstectomy (SARA) trial. BMC Cancer. 2020;20(1):735. doi:10.1186/s12885-020-07242-0

26. Jain PK, Sowdi R, Anderson ADG, MacFie J. Randomized clinical trial investigating the use of drains and fibrin sealant following surgery for breast cancer. Br J Surg. 2004;91(1):54-60. doi:10.1002/bjs.4435

\section{Publish your work in this journal}

Cancer Management and Research is an international, peer-reviewed open access journal focusing on cancer research and the optimal use of preventative and integrated treatment interventions to achieve improved outcomes, enhanced survival and quality of life for the cancer patient.
The manuscript management system is completely online and includes a very quick and fair peer-review system, which is all easy to use. Visit http://www.dovepress.com/testimonials.php to read real quotes from published authors. 